\title{
On demand electrochemical release of drugs from porous reduced graphene oxide modified flexible electrodes
}

Authors:

Samia Boulahneche ${ }^{\text {ab }}$, Roxana Jijie ${ }^{\text {a }}$, Alexandre Barras ${ }^{\text {a }}$, Fereshteh Chekin ${ }^{\text {ac }}$, Santosh K. Singh ${ }^{\text {d }}$, Julie Bouckaert $^{\mathrm{e}}$, Mohamed Salah Medjram ${ }^{\mathrm{b}}$, Sreekumar Kurungot ${ }^{\mathrm{df}}$, Rabah Boukherroub *a and Sabine Szunerits *a

a. Univ. Lille, CNRS, Centrale Lille, ISEN, Univ. Valenciennes, UMR 8520, IEMN, F-59000 Lille, France. E-mail: rabah.boukherroub@univ-lille1.fr; sabine.szunerits@univ-lille1.fr

b. Laboratoire de Génie Chimique et Environnement Skikda (LGCES), Université de 20 août, 1955-Skikda, Algeria

c. Department of Chemistry, Ayatollah Amoli Branch, Islamic Azad University, Amol, Iran

d. Physical and Materials Chemistry Division, CSIR-National Chemical Laboratory, Dr Homi Bhabha Road, Pune 411008, India

e. Unité de Glycobiologie Structurale et Fonctionnelle (UGSF), UMR 8576 du CNRS et Université Lille, 50 Av. de Halley, 59658 Villeneuve d'Ascq, France

f. Academy of Scientific and Innovative Research, Anusandhan Bhawan, 2 RafiMarg, New Delhi 110001 , India

DOI: 10.1039/C7TB00687J (Paper) J. Mater. Chem. B, 2017, 5, 6557-6565

\begin{abstract}
Despite the advantages of an electrochemical control for drug release, only a handful of electrochemical-based release systems have been developed so far. We report herein on the development of an electrochemically activatable platform for on-demand delivery of drugs. It is based on flexible gold thin film electrodes coated with porous reduced graphene oxide (prGO) nanosheets onto which the drug of interest has been integrated beforehand. Two different drugs are investigated here: ondansetron hydrochloride (ODS), a selective 5-HT3 receptor antagonist used for preventing nausea and vomiting caused by chemotherapy and radiotherapy, and ampicillin (AMP), an antibiotic to prevent and treat a number of bacterial infections such as respiratory tract infections, urinary tract infections, and meningitis. In the case of ODS, application of a negative potential bias of $-0.8 \mathrm{~V}$ results in a sustained slow ODS release with an ODS flux of $47 \mu \mathrm{g} \mathrm{cm-2} \mathrm{h}-1$. In the case of AMP, we show that polyethyleneimine modified prGO (prGO/PEI) is an extremely efficient matrix. Upon the application of $+0.8 \mathrm{~V}, 24 \%$ of AMP could be released from the electrical interface in a time span of $2 \mathrm{~h}$. The released AMP kept its antibacterial activity as demonstrated by antimicrobial tests. These examples illustrate the major benefits of the developed approach for biomedical applications.
\end{abstract}

\section{Introduction}

The development of a general platform for efficient on-demand delivery of a variety of drugs remains an unachieved task. While a large variety of stimuli carriers for drug delivery at the nano and microscale have been designed and tested, for each drug, special formulations have to be designed taking into 
consideration the physico-chemical properties of the therapeutics. The development of a loading matrix allowing the integration of a variety of active principles would consequently be of high interest. Considerable efforts have been directed in recent years towards the use of porous structures as drug loading matrices due to their high surface area, tunable pore size and well-defined surface architectures. $\stackrel{1-5}{ }$ Porous graphene based nanostructures, such as porous reduced graphene oxide (prGO), withstand high mechanical strength and also show superior electrochemical properties when compared with rGO .6 .7 While prGO architectures have been widely used for the fabrication of high-performance energy storage devices $\frac{8-11}{2}$ and for sensing, $\frac{7.12}{2}$ their benefits for the loading and release of drugs have not been focused upon yet. As the resident porosity increases the specific surface area, higher drug loading is expected to be achieved on such nanostructured materials.

In this work, we demonstrate the use of porous reduced graphene oxide (prGO) for drug loading. Electrochemical stimulate has become a particularly appealing method for the on demand delivery of therapeutics $\frac{13-18}{}$ and will be used here as a release strategy. Undoubtedly, prGO nanostructures are ideal platforms for the loading and electrochemically triggered release of drugs. Their high surface area together with an abundance of localized $\pi$-electrons at the surface of the nanosheets enables $\pi-\pi$ interactions with the aromatic part of drugs, allowing high loading capacitance; and the conducting properties make them ideal for electrochemical applications. Drop-casting a drug loaded prGO matrix onto electrodes made of gold coated Kapton (K/Au) (Fig. 1) results in flexible interfaces, which can be electrochemically addressed. Indeed, despite all the advantages that electrochemistry offers, such as low-cost, excellent control over applied potential or current, miniaturization etc., only a handful of electrochemical-based release systems have been shown to release drugs of therapeutic relevant concentrations.

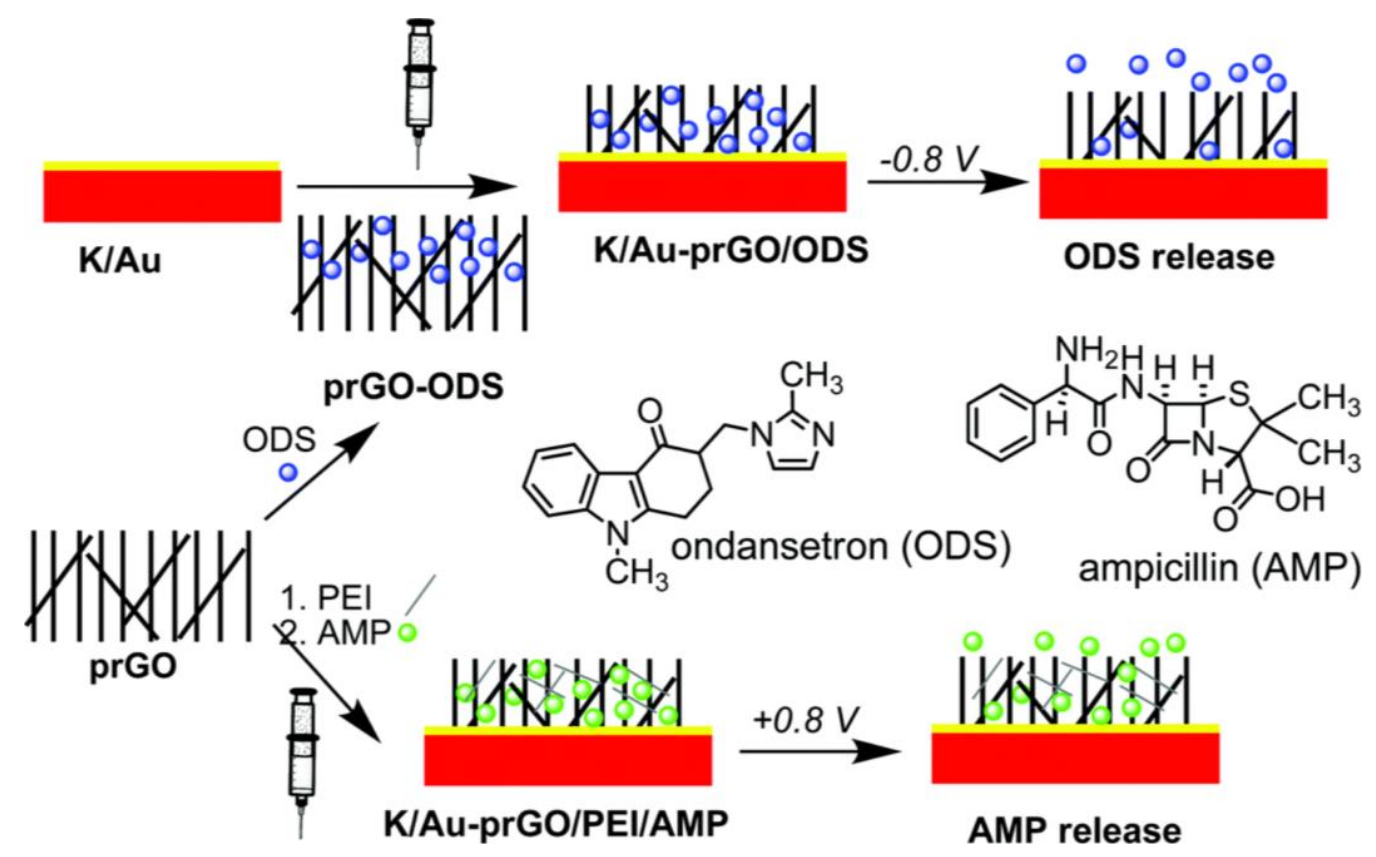

Fig. 1 Schematic illustration of the fabrication of flexible Kapton/Au-based interfaces modified with porous reduced graphene oxide (prGO) loaded with ondansetron (ODS), and polyethyleneimine (PEI) modified prGO loaded with ampicillin (AMP) for electrochemical triggered on demand release.

Two different drugs were tested for loading onto prGO and subsequent electrochemical release: ondansetron (ODS) and ampicillin (AMP). ODS, a serotonin subtype 3 (5-HT3) receptor antagonist, is commonly used in the treatment of chemotherapy-induced nausea vomiting. Chemotherapy-induced nausea vomiting is, next to others, one of the most painful side effects 
of chemotherapy, causing significant discomfort and anxiety. A study by Rogers and Blackburn shows that about $70 \%$ of patients receiving chemotherapy will experience high nausea levels and are inclined to give up treatment. $\frac{19}{}$ Even though ODS is validated as a good candidate for patients receiving highly emetogenic agents, its use has been limited in people having difficulties in swallowing after chemotherapy. Besides oral delivery, numerous alternative delivery systems have been investigated, including transdermal ${ }^{20-24}$ and nasal administration. ${ }^{25}$ We have recently developed a flexible transdermal patch for the photothermal triggered release of ODS. We have demonstrated that these ODS loaded patches have a high drug delivery performance upon irradiation with a continuous laser beam at $980 \mathrm{~nm}$ due to an induced photothermal heating effect. $\underline{24}$

The other drug investigated is the antibiotic AMP, as treatment of bacterial infections is still one of the most challenging tasks in the biomedical field. With the overuse of antibiotics and the resulting growing number of multidrug-resistant bacteria, the development of on demand antibiotic delivery systems is a practical strategy for reducing the generation of antibiotic resistance and increasing the lifespan of newly developed antibiotics. $\frac{26-28}{}$ Biodegradable polymers have been considered and investigated for the past decade as antibiotic delivery carriers for the local treatment of infections. ${ }^{26,29-31}$ In these systems, matrix degradation and erosion result in the release of encaged antibiotics with often low antibiotic release rates. We show here not only that a polyethyleneimine (PEI) modified prGO matrix has excellent loading capacity for AMP, but most importantly that upon application of $+0.8 \mathrm{~V}$, AMP release up to $24 \%$ can be reached in only $2 \mathrm{~h}$. More importantly, the fact that the electrochemically released antibiotic did not lose its activity for the destruction of pathogens was in addition validated by studying the bacterial viability of E. coli pathogens.

\section{Experimental section}

\subsection{Materials}

Ondansetron (ODS) hydrochloride, hydrogen peroxide $\left(\mathrm{H}_{2} \mathrm{O}_{2}\right)$, sodium hydroxide $(\mathrm{NaOH})$, hydrazine monohydrate, potassium hexacyanoferrate(II) $\left(\mathrm{K}_{4} \mathrm{Fe}(\mathrm{CN})_{6}\right)$, and branched polyethyleneimine (PEI, $\mathrm{M}_{\mathrm{w}}$

$\sim 25$ 000) were purchased from Sigma-Aldrich (Darmstadt, Germany) and used as received.

Graphene oxide (GO) powder was purchased from Graphenea, Spain and ampicillin (AMP) from Fisher Scientific.

Kapton ${ }^{\circledR} \mathrm{HN}$ polyimide foils with a thickness of $125 \mu \mathrm{m}$ were obtained from DuPont (Circleville, OH, USA).

\subsection{Synthesis of reduced graphene oxide (rGO)}

Reduced graphene oxide ( $\mathrm{rGO}$ ) was prepared from a $\mathrm{GO}$ precursor using hydrazine reduction. Briefly, to $5 \mathrm{~mL}$ GO aqueous suspension $\left(0.5 \mathrm{mg} \mathrm{mL}^{-1}\right)$ was added hydrazine hydrate $(0.50 \mathrm{~mL}, 32.1 \mathrm{mM})$ and heated in an oil bath at $100{ }^{\circ} \mathrm{C}$ for $24 \mathrm{~h}$ over which the reduced GO gradually precipitated out of the solution. The product was isolated by filtration over a PVDF membrane with a $0.45 \mu \mathrm{m}$ pore size, washed copiously with water $(5 \times 20 \mathrm{~mL})$ and methanol $(5 \times 20 \mathrm{~mL})$ and dried in an oven at $100{ }^{\circ} \mathrm{C}$ overnight.

\subsection{Synthesis of porous reduced graphene oxide (prGO)}


The synthesis of prGO was based on previous work by some of us. $\stackrel{32}{\mathrm{rGO}}$ powder $(100 \mathrm{mg})$ was dispersed in $\mathrm{H}_{2} \mathrm{O}_{2}(100 \mathrm{~mL} ; 30 \%)$, ultrasonicated for $30 \mathrm{~min}$ and the mixture was refluxed for $12 \mathrm{~h}$ at 60 ${ }^{\circ} \mathrm{C}$. The obtained solution was filtered and the recovered prGO powder was dialysed to remove $\mathrm{H}_{2} \mathrm{O}_{2}$ and to separate it from small sized graphene quantum dots.

\subsection{Loading of rGO or prGO with drugs}

2.4.1. Ondansetron (ODS). rGO or prGO $\left(0.5-1 \mathrm{mg} \mathrm{mL}^{-1}\right)$ was sonicated with ondansetron $(500 \mu \mathrm{g}$ $\mathrm{mL}^{-1}$ ) for $2 \mathrm{~h}$ while stirring. All samples were centrifuged at $13500 \mathrm{rpm}$ for $30 \mathrm{~min}$. The concentration of ODS loaded onto the rGO or prGO matrix was determined using UV/vis spectroscopy at $312 \mathrm{~nm}$.

2.4.2. Ampicillin (AMP). prGO and prGO/PEI matrices were loaded with ampicillin (AMP) by mixing them with $10 \mu \mathrm{L}$ of AMP solution $\left(10 \mathrm{mg} \mathrm{mL}^{-1}\right)$ and stirring the suspensions for $2 \mathrm{~h}$ at room temperature. The prGO/PEI matrix was obtained first by mixing the two substances at a volume ratio of $1 / 1(0.1-1$ $\mathrm{mg} \mathrm{mL}^{-1}$ ) and stirring for $30 \mathrm{~min}$ at room temperature. All samples were centrifuged at $13500 \mathrm{rpm}$ for 30 min. The concentration of AMP loaded onto the prGO/PEI matrix was determined using HPLC analysis.

\subsection{Modification of gold coated Kapton foils with rGO/ODS, prGO/ODS, prGO/AMP or prGO/PEI/AMP}

Kapton foils $\left(10 \times 10 \mathrm{~mm}^{2}\right)$ were first cleaned with acetone in an ultrasonic water bath for $30 \mathrm{~min}$, followed with isopropanol for $10 \mathrm{~min}$ and then dried under a nitrogen flow. Gold coated Kapton films were prepared by thermal evaporation of $5 \mathrm{~nm}$ of titanium and $50 \mathrm{~nm}$ of gold onto cleaned Kapton interfaces. Titanium was used as an adhesion layer between the gold surface and Kapton. Drop-casting of $\mathrm{rGO} / \mathrm{ODS}$, prGO/ODS, prGO/AMP or prGO/PEI/AMP onto Kapton/Au (three times) resulted in the $\mathrm{K} / \mathrm{Au}-\mathrm{rGO} / \mathrm{ODS}, \mathrm{K} / \mathrm{Au}$-prGO/ODS, K/Au-prGO/AMP and K/Au-prGO/PEI/AMP flexible electrodes used in this work.

\subsection{Instrumentation}

2.6.1 Scanning electron microscopy (SEM). SEM images were obtained using an electron microscope ULTRA 55 (Zeiss, France) equipped with a thermal field emission emitter and three different detectors (an EsB detector with a filter grid, a high efficiency In-lens SE detector and an Everhart-Thornley Secondary Electron Detector).

2.6.2 Transmission electron microscopy (TEM). High resolution transmission electron microscopy (HRTEM) analysis of the prepared samples was carried out using a FEI, TECNAI G2 F20 instrument operated at an accelerated voltage of $300 \mathrm{kV}(\mathrm{Cs}=0.6 \mathrm{~mm}$, resolution $1.7 \AA$ ). For the TEM analysis the sample was prepared by drop coating $10 \mu \mathrm{L}$ of the dispersed solution of $1 \mathrm{mg}$ material in $5 \mathrm{~mL}$ isopropyl alcohol over carbon coated 200 mesh $\mathrm{Cu}$ grids. The catalyst drop coated $\mathrm{Cu}$ grid was dried and the prepared sample was used for imaging purposes.

2.6.3 UV/Vis measurements. Absorption spectra were recorded using a Perkin Elmer Lambda UV-Vis 950 spectrophotometer in a $1 \mathrm{~cm}$ quartz cuvette. The wavelength range was $200-1100 \mathrm{~nm}$.

2.6.4 Zeta-potential measurements. Zeta-potential measurements were performed using a Zeta-sizer Nano-ZS (Malvern Instruments Inc. Worcestershire, UK). Samples were diluted to $10 \mu \mathrm{gL}^{-1}$ and measured in Milli-Q water at a $\mathrm{pH}$ of 7.0.

2.6.5 Electrochemical measurements. Electrochemical measurements were performed with a potentiostat/galvanostat (Autolab, The Netherlands). A conventional three-electrode configuration was employed using a silver wire, a platinum mesh as a reference and an auxiliary electrode, respectively.

\subsection{UV method for quantification of ODS}

4

DOI: 10.1039/C7TB00687J - Journal: $\underline{\text { J. Mater. Chem. B }}$ - Post-print 
The concentration of ODS loaded onto rGO or prGO films and released from the $\mathrm{K} / \mathrm{Au}-\mathrm{rGO} / \mathrm{ODS}$ or $\mathrm{K} / \mathrm{Au}-\mathrm{prGO} / \mathrm{ODS}$ electrodes was determined using UV-vis spectroscopy. First a calibration curve of a series of ODS solutions of different concentrations was established. In the case of determination of ODS loaded onto rGO or prGO, the concentration of ODS remaining in the supernatant solution used for loading was measured, allowing the determination of the ODS concentration in rGO or prGO film according to:

$[\mathrm{ODS}]_{\mathrm{G}}=[\mathrm{ODS}]_{\mathrm{initial}}-[\mathrm{ODS}]_{\text {supernatant }}$

with $[\mathrm{ODS}]_{\mathrm{G}}=$ concentration of ODS on the $\mathrm{rGO}$ or prGO matrix $\left(\mu \mathrm{g} \mathrm{mL} \mathrm{L}^{-1}\right)$

with $[\mathrm{ODS}]_{\text {initial }}=$ initial concentration of ODS in solution $\left(500 \mu \mathrm{g} \mathrm{mL} \mathrm{m}^{-1}\right)$

with $[\mathrm{ODS}]_{\text {supernatant }}=$ concentration of ODS in the supernatant $\left(\mu \mathrm{g} \mathrm{mL} \mathrm{L}^{-1}\right)$

In the case of release, the concentration of ODS in the electrolyte solution was determined directly using UV/Vis spectroscopy.

\subsection{High-performance liquid chromatography (HPLC) for quantification of AMP loading}

The concentration of AMP loaded onto prGO/PEI was determined using an HPLC system (Shimadzu, Tokyo, Japan) equipped with a $5 \mu \mathrm{m} \mathrm{C}_{4}$ QS Uptisphere ${ }^{\circledR} 300 \AA$, $250 \mathrm{~mm} \times 4.6 \mathrm{~mm}$ column (Interchim, Montluçon, France) heated to $40^{\circ} \mathrm{C}$. The mobile phase consisted of a mixture of eluent A (trifluoroacetic acid $0.1 \%$ in water) and eluent $\mathrm{B}$ (trifluoroacetic acid $0.1 \%$ in acetonitrile) at a flow rate of $1 \mathrm{~mL} \mathrm{~min}{ }^{-1}$. The samples were injected at a volume of $40 \mu \mathrm{L}$ and the detection wavelength was $227 \mathrm{~nm}$. First a calibration curve of a series of AMP solutions of different concentrations was generated. The concentration of AMP remaining in the supernatant solution used for loading was measured, allowing the determination of the AMP concentration in the prGO/PEI film as described for ODS.

\subsection{Electrochemical release}

2.9.1. Ondansetron (ODS). Release experiments were performed in $1 \mathrm{~mL}$ PBS (0.1 M, pH 7.4). The quantity of ODS released into the electrolyte solution was determined by UV-vis spectroscopy at 312 $\mathrm{nm}$, using a calibration curve with an ODS concentration ranging from 1 to $60 \mu \mathrm{g} \mathrm{m}^{-1}$.

2.9.2. Ampicillin (AMP). Release experiments were performed in $1 \mathrm{~mL}$ PBS (0.1 M, pH 7.4). The quantity of AMP released into the electrolyte solution was determined by UV-Vis analysis (see the ESI, Fig. S1A), using a calibration curve with an AMP concentration ranging from 5 to $100 \mu \mathrm{g} \mathrm{mL}^{-1}$ (see the ESI, $\doteq$ Fig. S2, y (area) $=1.11+0.589 \times[$ AMP $\left.]\left(\mu g \mathrm{~mL}^{-1}, \mathrm{R}=0.999\right)\right)$.

\subsection{Bacterial growth conditions}

A single C43 (DE3) E. coli colony from an LB agar plate was inoculated overnight in Luria Bertani (LB) broth at $37^{\circ} \mathrm{C}$ with moderate shaking (180 rpm). Upon 50-fold dilution, incubation was prolonged until $\mathrm{OD}_{600}$ had reached $0.6-1$.

\subsection{Bacteria cell viability}

Following electrochemical release of AMP, survival of the bacteria was measured by determining the titer of viable bacteria able to grow. A 10-fold dilution series of the bacterial solutions in phosphate buffer saline was spotted in $10 \mu \mathrm{L}$ aliquots on LB-agar medium. Visual counting of the number of colonies upon overnight incubation at $37{ }^{\circ} \mathrm{C}$ allowed reading out of the initial and final concentrations of the E. coli strain in $\mathrm{cfu}^{\mathrm{m}} \mathrm{L}^{-1}$. 


\section{Results and discussion}

\subsection{Loading of ODS onto rGO and prGO}

Fig. 2A displays TEM images of hydrazine reduced graphene oxide (rGO) and the resulting rGO that was further treated with hydrogen peroxide $\left(\mathrm{H}_{2} \mathrm{O}_{2}\right)$ at elevated temperature. The generation of oxidizing free radicals $\left(\mathrm{OH}^{\circ}, \mathrm{O}^{\circ}, \mathrm{HO}_{2}{ }^{\circ}\right)$ leads to the formation of an increasing number of epoxy groups on rGO, which upon hydrolysis to hydroxyl groups result in a subsequent breaking of $\mathrm{C}-\mathrm{C}$, as evidenced in the TEM images. While rGO displays transparent continuous nanosheets, uniformly distributed nanopores (4-6 nm in diameter) are observed after $\mathrm{H}_{2} \mathrm{O}_{2}$ treatment. Drop-casting $\mathrm{rGO}$ and prGO onto gold coated Kapton film (Fig. 2B) results in bendable and flexible electrical interfaces that can be easily implemented onto the human body. The choice of 4,4'-oxydiphenylene-pyromellitimide, registered under the name Kapton, was based on its high thermal stability $\left(>300{ }^{\circ} \mathrm{C}\right)$ and chemical resistance, as well as excellent flexibility and adhesive properties. Fig. $2 \mathrm{C}$ exhibits the cyclic voltammetric responses of $\mathrm{K} / \mathrm{Au}$ electrodes before and after coating with $\mathrm{rGO}$ or prGO using $\left[\mathrm{Fe}(\mathrm{CN})_{6}\right]^{3-/ 4-}$ as the redox couple. Well defined electrochemical signals were observed in all three cases, with a considerable increase in redox current for K/Au coated with prGO. The increased current correlated with an increased surface area (Fig. 2D) and good electronic properties of prGO as reported previously by us. ${ }^{7}$ Interestingly, even bending the electrode did not change the electrochemical behavior of the electrical interface.

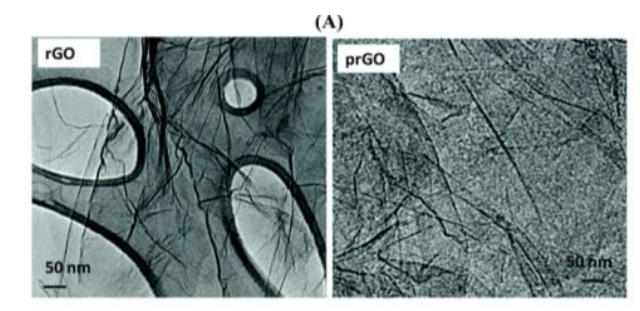

(B)

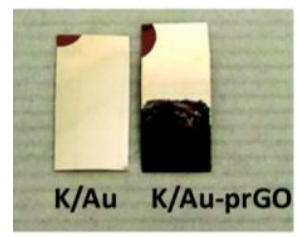

(C)

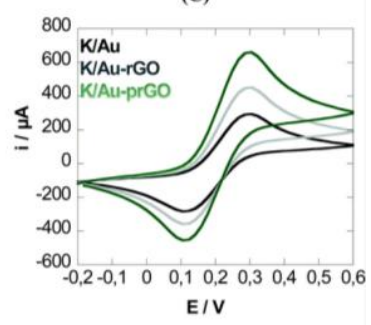

(D)

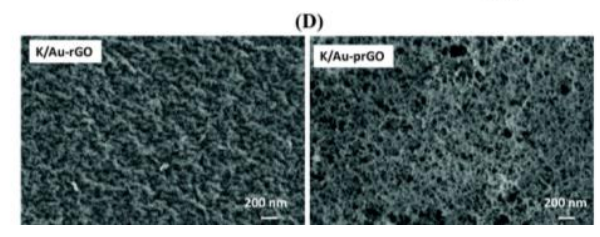

Fig. 2 (A) Transmission electron microscopy (TEM) images of reduced graphene oxide (rGO) and porous reduced graphene oxide (prGO); (B) photographs of the $\mathrm{K} / \mathrm{Au}$ flexible electrode before and after coating with prGO by drop casting; (C) cyclic voltammograms of $\mathrm{K} / \mathrm{Au}$ (black), $\mathrm{K} / \mathrm{Au}-\mathrm{rGO}$ (grey) and $\mathrm{K} / \mathrm{Au}-\mathrm{prGO}$ (green) using $[\mathrm{Fe}(\mathrm{CN}) 6] 3-/ 4-(5 \mathrm{mM}) / \mathrm{PBS}(0.1 \mathrm{M})$, scan rate $=50 \mathrm{mV} \mathrm{s}-1$; (D) SEM images of $\mathrm{K} / \mathrm{Au}-\mathrm{rGO}$ and $\mathrm{K} / \mathrm{Au}-\mathrm{prGO}$.

Both matrices, rGO and prGO, were loaded with ondansetron (ODS) using different weight ratios. ODS $\left(500 \mu \mathrm{g} \mathrm{mL}^{-1}\right)$ was loaded onto $\mathrm{rGO}$ or prGO by sonicating a suspension of the respective graphene based nanomaterial in water ( $\mathrm{pH}$ 7.4) for $4 \mathrm{~h}$. The positively charged pyridine network of ODS is believed to interact with $\mathrm{rGO}$ and $\mathrm{prGO}$ through $\pi-\pi$ stacking and/or electrostatic interactions, although 
other contributions such as hydrogen bonding and/or van der Waals interactions cannot be excluded. UV/Vis spectroscopy was used for the quantification of the remaining ODS in solution (Fig. 3A), where a linear relationship between the absorption band at $312 \mathrm{~nm}$ and ODS concentration was determined between 1-60 $\mu \mathrm{g} \mathrm{mL} \mathrm{m}^{-1}$. As seen in Fig. 3B, at a rGO/ODS or prGO/ODS weight ratio of 0.5 (500 $\mu \mathrm{g}$ $\mathrm{mL}^{-1} \mathrm{rGO}$ or prGO and $250 \mu \mathrm{g} \mathrm{mL}^{-1}$ of ODS), prGO showed a three times higher loading capacity for ODS. Using a weight ratio of $\mathrm{prGO} / \mathrm{ODS}=1 / 1$, a loading efficiency of $99 \%$ was determined. The loading capacity of ODS onto prGO is $\mathrm{pH}$ dependent, with a higher ODS loading at a $\mathrm{pH}$ of $\geq 7$ (Fig. 3C), most likely due to the better solubility of ODS at a more alkaline $\mathrm{pH}$. The improved ODS loading on prGO prompted us to use these nanostructures for further characterization and electrochemically triggered release studies.
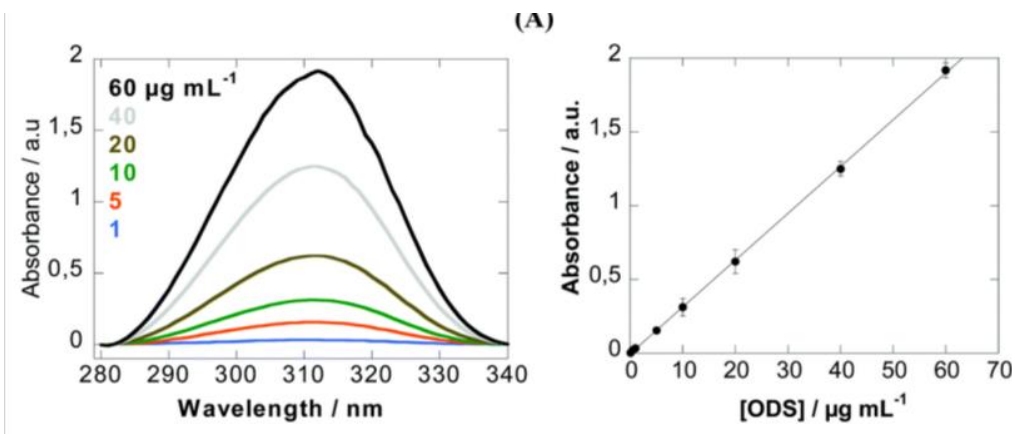

(B)

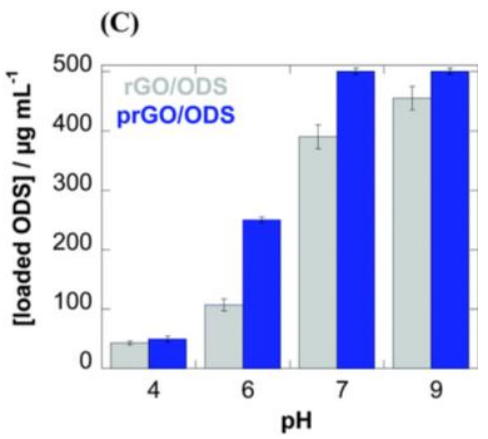

Fig. 3 (A) UV/Vis spectra of different concentrations of ODS and the corresponding calibration curve; (B) loading capacity of rGO (grey) and prGO (blue) with ODS $(500 \mu \mathrm{g} \mathrm{mL}-1)$ at $\mathrm{pH} 7$ upon varying the $\mathrm{rGO} / \mathrm{ODS}$ and $\mathrm{prGO} / \mathrm{ODS}$ ratios; (C) influence of $\mathrm{pH}$ on ODS loading $(500 \mu \mathrm{g} \mathrm{mL}-1)(\mathrm{pH}$ was adjusted by the addition of $\mathrm{HCl}$ and $\mathrm{NaOH}$ to $\mathrm{PBS}$ solutions).

\subsection{Electrochemical triggered release of ODS}

To evaluate the electrochemical release performance of the K/Au-prGO/ODS interface under physiological conditions ( $\mathrm{pH}=7.4$ ), different voltage pulses were applied to the electrical interface and the amount of ODS released was determined using UV/Vis absorption spectroscopy. The cyclic voltammetry (CV) in PBS (0.1 M, pH 7.4) of a K/Au-prGO/ODS (Fig. 4A) indicates that ODS has no electrochemical activity. In comparison to $\mathrm{K} / \mathrm{Au}$, the oxygen reduction band at around $-0.4 \mathrm{~V}$ is increased on $\mathrm{K} / \mathrm{Au}-\mathrm{prGO} / \mathrm{ODS}$. Before determining the amount of ODS released during electrochemical activation, the stability of the K/Au-prGO/ODS electrodes was established (Fig. 4B). Immersion of the interfaces for $6 \mathrm{~h}$ at a pH of 7 without the application of a potential resulted in only $2 \pm 1 \%$ ODS release, indicating that passive release results in a very low amount of free ODS. Application of a negative potential of $-0.8 \mathrm{~V}$ vs. SCE resulted in a somewhat higher amount of ODS released when compared with the application of $+0.8 \mathrm{~V}$ vs. SCE. However, even under these conditions, a considerable amount of ODS was released from the prGO-ODS matrix. The larger drug release under negative potential bias is believed to be due to local $\mathrm{pH}$ and charge variations. At a potential bias of $-0.8 \mathrm{~V}$, reduction of 
dissolved oxygen occurs, generating $\mathrm{OH}^{-}$ions. $\frac{15}{\text { The resulting lower }} \mathrm{pH}$ close to the electrode surface might favor the release of ODS from the prGO matrix. Indeed, release into oxygen-free solutions for 1 $\mathrm{h}$ results in only $3 \%$ ODS release compared with $12 \%$ in aerated solutions. Furthermore, performing ODS release into PBS solutions at a pH of 9 results in a higher ODS release overall (Fig. 4C).

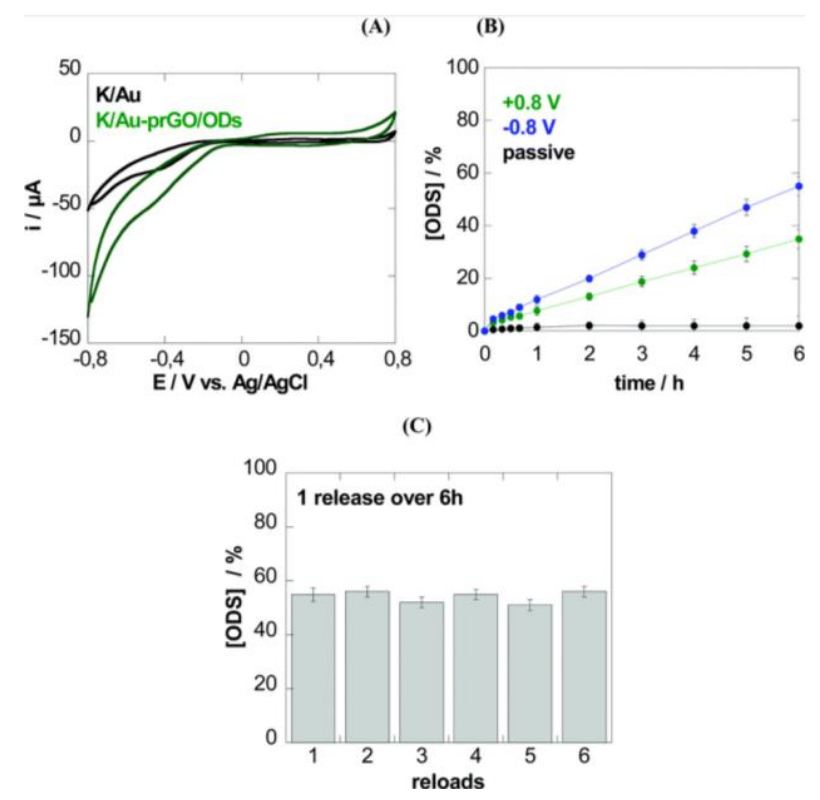

Fig. 4 (A) Cyclic voltammograms of K/Au (black) and K/Au-prGO/ODs (green) in PBS (0.1 M, pH 7.4), scan rate $=50 \mathrm{mV} \mathrm{s}-1$; (B) electrochemical triggered ODS release over time into PBS $(0.1 \mathrm{M}, \mathrm{pH}$ 7.4) upon the application of $+0.8 \mathrm{~V}$ (green) or $-0.8 \mathrm{~V}$ (blue), and under passive diffusion (no potential applied); (C) amount of ODS released upon reloading K/Au with prGO/ODS several times.

On the other hand, at a potential bias of $+0.8 \mathrm{~V}$, the positively charged interface might overcome electrostatic interaction between ODS ( $\mathrm{pK}_{\mathrm{a}}$ of $\left.\sim 7.4\right)^{33}$ and prGO, leading to a significant release of ODS with time. Notably, passive release (no potential bias) results in a small fraction of ODS released, underlying the stability of the interface under the chosen conditions and the need of an electrochemical bias for on demand release.

Compared with the electrochemically triggered release of insulin from rGO, with up to $70 \%$ release in $30 \mathrm{~min}$, the release of the smaller ODS molecule is rather slow. It is also in contrast to the recently reported photothermal release of ODS on photothermally activatable skin patches: ${ }^{-4}$ irradiation for 30 min resulted in a release of $15 \%$ ODS, while electrochemical release of ODS after 30 min was between 5 and 7\%. However, while the photothermal approach resulted in a release maximum after $30 \mathrm{~min}$ irradiation, the release of ODS as shown here is constant over a long period of time. From Fig. 4B, the flux of ODS from the electrode into solution can be determined from the slope. After a lag time of about $1 \mathrm{~h}$, the ODS flux (J) into solution is determined as $47 \mu \mathrm{g} \mathrm{cm}^{-2} \mathrm{~h}^{-1}$. Such a flux is highly promising for follow up transdermal studies where ODS fluxes between $1 \mu \mathrm{g} \mathrm{cm}{ }^{-2} \mathrm{~h}^{-1}$ and $4 \mu \mathrm{g} \mathrm{cm} \mathrm{cm}^{-2} \mathrm{~h}^{-1}$ are reported. $\underline{24,25,34}$

Considering that the usual oral dose of ODS is between 16 and $32 \mathrm{mg}$ a day and the oral bioavailability of ODS is $60 \%$, for an effective ODS delivery system, about 10-20 mg a day should be delivered into the blood circulation, i.e. $2.5-5 \mathrm{mg}$ every 6 h. $\frac{35}{} \mathrm{~A} \mathrm{~K} / \mathrm{Au}-\mathrm{prGO} / \mathrm{ODS}$ electrode of $1 \mathrm{~cm}^{2}$ delivers about $282 \mu \mathrm{g}$ ODS in $6 \mathrm{~h}$. An electrode of around $10 \mathrm{~cm}^{2}$ in size is theoretically needed to deliver the daily amount required. What makes the architecture also of 
practical interest is that the K/Au electrode can be recharged with prGO/ODS and subsequently used for ODS release for six cycles without any loss of its performance (Fig. 4C).

\subsection{Loading and release of AMP from prGO/PEI/AMP modified electrodes}

Antibiotics incorporated into local delivery systems ideally demonstrate broad and sufficient efficacy as well as chemical stability. We opted here for the integration of ampicillin (AMP) into the electrochemical release matrix. AMP is part of the aminopenicillin family and the presence of the aromatic ring together with amino and carboxylic acid functions makes AMP most likely to interact with prGO through $\pi-\pi$ stacking and/or electrostatic interactions. The preservation of the amino group upon integration into prGO is important as this function helps the drug to penetrate the outer membrane of Gram-negative bacteria. The loading capacity of prGO for AMP as determined from HPLC analysis (Fig. 5A), where a linear relationship between $5-100 \mu \mathrm{g} \mathrm{mL}^{-1}$ is observed, is however rather low (Fig. 5B). AMP has acid carboxylic groups with a $\mathrm{pK}_{\mathrm{a}} \approx 4-5$, being thus ionized at physiological $\mathrm{pH}$. The presence of the basic amino group $\left(\mathrm{pK}_{\mathrm{a}} \approx 9\right)$ makes AMP a zwitterion at physiological $\mathrm{pH}$, as amino groups are also predominately positively ionized. As prGO has a zeta potential of $-19 \pm 2 \mathrm{mV}$, electrostatic repulsion might prevail in this case. We consequently loaded AMP onto prGO previously modified with polyethyleneimine (PEI) by simple stirring for $2 \mathrm{~h}$ at room temperature. The zeta potential of the formed prGO/PEI matrix was $+41 \pm 2 \mathrm{mV}$ due to the presence of PEI. On these matrices, an AMP loading capacity of $100 \%$ was achieved using a prGO/AMP weight ratio of $\geq 2.5\left(250 \mu \mathrm{g} \mathrm{mL} \mathrm{mrGO}^{-1} \mathrm{PEI}\right.$ and $100 \mu \mathrm{g} \mathrm{mL}^{-1}$ of AMP) (Fig. 5B).

(A)
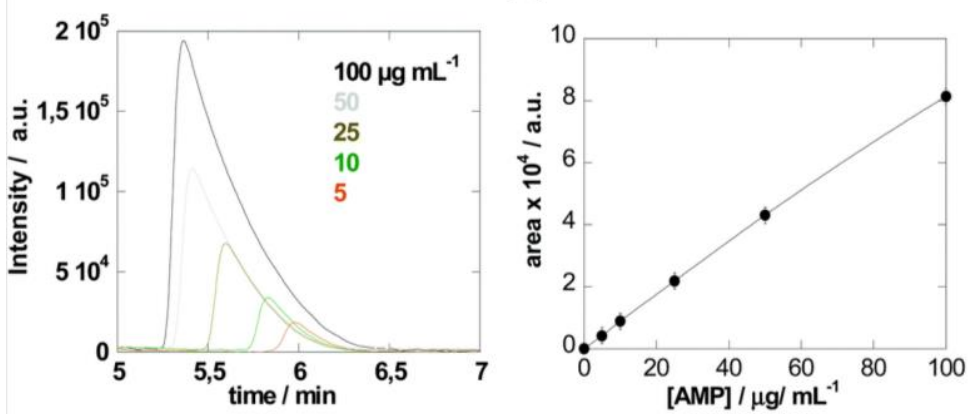

(B)

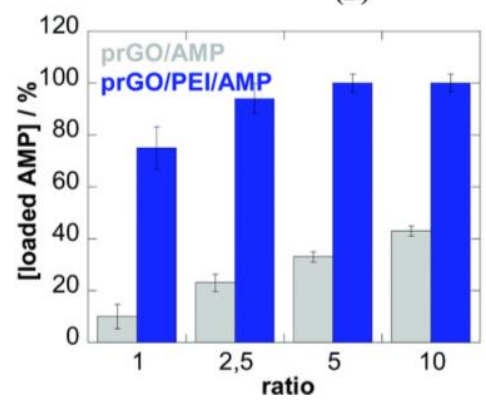

(C)

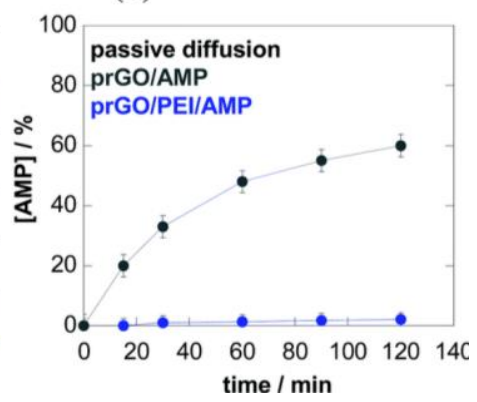

Fig. 5 (A) HPLC curve of ampicillin (AMP) at different concentrations and the corresponding calibration curve; (B) loading capacity of prGO (grey) and prGO/PEI (blue) matrix with AMP (100 $\mu \mathrm{g}$ $\mathrm{mL}-1$ ) upon varying the ratio of prGO and prGO/PEI with AMP; (C) stability of electrochemical interfaces modified by drop-casting of prGO/AMP (grey) or prGO/PEI/AMP (blue) upon immersion for $2 \mathrm{~h}$ into PBS (0.1 M, pH 7.4) without application of a potential (passive diffusion).

The addition of PEI to the prGO matrix also had a positive effect on the stability of the AMP modified electrodes (Fig. 5C): while up to $60 \%$ of AMP was released from prGO/AMP, in the case of prGO/PEI/AMP only $2 \pm 1 \%$ was released over a time span of $2 \mathrm{~h}$. 
The application of $-0.8 \mathrm{~V}$ vs. SCE for $2 \mathrm{~h}$ to the prGO/PEI/APM modified electrical interface showed no significant AMP release as determined by UV/Vis spectroscopy (see the ESI, 1 Fig. S1), the amount being comparable to that of passive release (Fig. 5C). This was in contrast with ODS, where the application of $-0.8 \mathrm{~V}$ vs. SCE resulted in a significant ODS release over time (Fig. 4B). The higher solubility of ODS under alkaline conditions, generated locally upon the application of a potential bias of $-0.8 \mathrm{~V}$ due to the generation of $\mathrm{OH}-$ ions, is believed to be the underlying potential controlled release mechanism in the case of ODS. This does not apply to AMP. Furthermore, the high $\mathrm{pH}$ buffering capacity of PEI is believed to play an additional important role to limit AMP release under the application of a negative potential. On the other hand, biasing the $\mathrm{prGO} / \mathrm{PEI} / \mathrm{AMP}$ at $+0.8 \mathrm{~V}$ vs. SCE exhibits a release of $\approx 24 \%$ (equivalent to $24 \mu \mathrm{g} \mathrm{mL}^{-1}$ ) over a $2 \mathrm{~h}$ time span (Fig. 6A). The positively charged interface seems to be favorable to zwitterions such as AMP to be detached from the electrode surface.

(A)

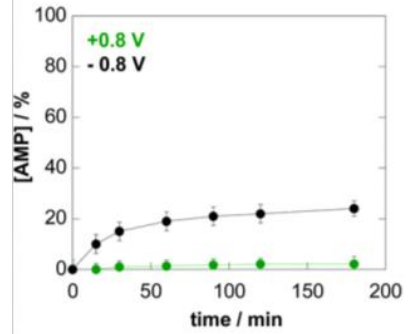

(C)

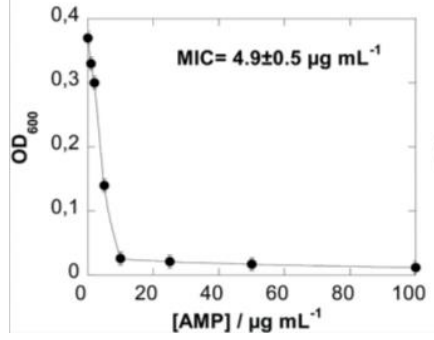

(B)

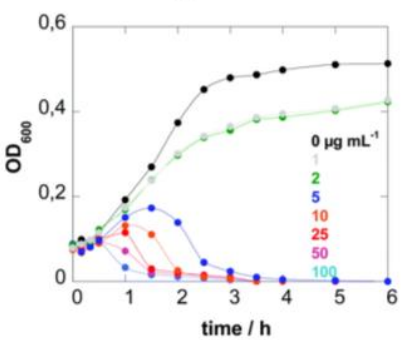

(D)

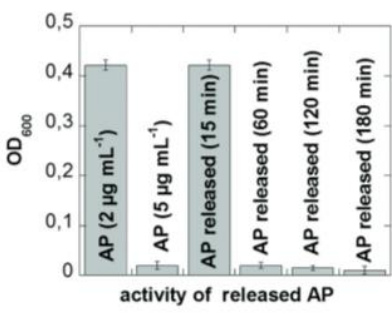

Fig. 6 (A) Electrochemical triggered AMP release from K/Au-prGO/PEI/AMP with $100 \mu \mathrm{g} \mathrm{mL}-1$ incorporated AMP over time into PBS $(0.1 \mathrm{M}, \mathrm{pH} 7.4)$ upon application of $+0.8 \mathrm{~V}$ (green) or $-0.8 \mathrm{~V}$ (blue); (B) planktonic growth of E. coli (inoculum of $1 \times 108 \mathrm{cfu} \mathrm{mL}-1$ ) in the absence and presence of different concentrations of AMP (0-100 $\mu \mathrm{g} \mathrm{mL}-1)$; (C) change of OD600 at $2 \mathrm{~h}$ (extracted from (B)); (D) comparison of the action of free AMP $(2 \mu \mathrm{g} \mathrm{mL}-1$, negative control), AMP ( $5 \mu \mathrm{g} \mathrm{mL}-1$; positive control) and electrochemically released AMP at different time intervals when incubated with E. coli (1 $\times 108 \mathrm{cfu} \mathrm{mL}-1$ ) for $2 \mathrm{~h}$.

While aminopenicillins are generally stable in the dry state, the drugs are stable only for short periods of time in solution. Following electrochemical release of AMP, survival of the bacteria was thus measured by determining the titer of viable bacteria able to grow. The minimum inhibitory concentration of AMP at which $50 \%$ of E. coli C43 isolates were inhibited was experimentally determined as $\mathrm{MIC}_{50}$ $=4.9 \pm 0.5 \mu \mathrm{g} \mathrm{mL} \mathrm{m}^{-1}$ (Fig. 6B), consistent with previous reports. Fig. 6C shows the $\mathrm{OD}_{600}$ values determined after incubation of E. coli for $2 \mathrm{~h}$ with different AMP samples using $2 \mu \mathrm{g} \mathrm{mL}^{-1}$ AMP as a negative control (below $\mathrm{MIC}_{50}$ value) and $5 \mu \mathrm{g} \mathrm{mL}^{-1} \mathrm{AMP}$ as a positive control ( $\mathrm{MIC}_{50}$ value). In accordance with the electrochemical release profile, about $2 \mu \mathrm{g} \mathrm{mL}^{-1}$ were released in the first 15 min, below the $\mathrm{MIC}_{50}$ value, while after $1 \mathrm{~h}$ the critical $5 \mu \mathrm{g} \mathrm{mL} \mathrm{m}^{-1}$ AMP was released from the matrix.

\section{Conclusion}

In summary, novel porous reduced graphene oxide based electrochemical interfaces for the efficient and on-demand delivery of therapeutics have been developed. We demonstrated the adaptability of this 
approach by loading the matrix with two different drugs of therapeutic interest: ondansetron, a druglimiting chemotherapy-induced nausea and vomiting, and ampicillin, a broad-band antibiotic against Gram-positive and -negative pathogens. Biasing the electrical interface at $-0.8 \mathrm{~V}$ resulted in a constant ODS flux of $47 \mu \mathrm{g} \mathrm{cm}^{-2} \mathrm{~h}^{-1}$ from the interface into the solution. To deliver the therapeutic ODS dose of $415-830 \mu \mathrm{g} \mathrm{h}^{-1}$ in the blood circulation, a $10 \mathrm{~cm}^{2}$ large electrode would be required. While feasible to construct, such a system is rather large, and several electrodes rather than one big one should be applied in a real case therapy. The addition of skin enhancer molecules such as Tween might also be favorable for an increased ODS release over time, making the approach of higher interest for therapeutic means.

In the case of ampicillin, PEI modified prGO was found to be a better suited loading matrix, where upon application of $+0.8 \mathrm{~V}$, concentrations far above the minimum inhibitory concentration of AMP for E. coli could be released in a time span of $3 \mathrm{~h}$. In this case, the size of the interface is already well adapted for real therapy. We believe that the approach developed in this study can be applied to any active principle/drug of interest and contribute to different biomedical therapies. Experiments on possible transdermal ODS and AMP delivery using electrochemically released ODS are currently under way. These might open up new avenues for the development of electrochemical assisted transdermal delivery of drugs on demand.

\section{Acknowledgements}

Financial support from the Centre National de la Recherche Scientifique (CNRS), the University Lille 1, the Hauts-de-France region, the CPER "Photonics for Society", the Agence National de la Recherche (ANR) and the EU union through FLAG-ERA JTC 2015-Graphtivity, and the Marie Sklodowska-Curie action (H2020-MSCA-RISE-2015, PANG-690836) are acknowledged. Samia Boulahneche thanks the Algerian Government for a $\mathrm{PhD}$ scholarship.

\section{References}

1. R. Gurny, E. Doelker and N. A. Peppas, Biomaterials, 1981, 3, 27-32 DOI: https://doi.org/10.1016/0142-9612(82)90057-6.

2. J. Salonen, L. Laitinen, A. M. Kaukonen, J. Tuura, M. Bjorkqvist, T. Heikkila, K. VähäHeikkilä, J. Hirvonen and V. P. Lehto, J. Controlled Release, 2005, 108, 362-374 DOI: https://doi.org/10.1016/j.jconrel.2005.08.017

3. S. Tang, B. Tian, Q. F. Ke, Z. A. Zhu and Y. P. Guo, RSC Adv., 2014, 4, 41500-41509 DOI: 10.1039/C4RA05493H.

4. M. Xu, M. Dan Feng, R. Dai, H. Wu, D. Zhao and G. Zheng, Nanoscale, 2011, 3, 3329-3333 DOI: $10.1039 / \mathrm{C} 1 \mathrm{NR} 10477 \mathrm{~B}$.

5. P. Horcajada, T. Chalati, C. Serre, B. Gillet, C. Sebrie, T. Baati, J. F. Eubank, D. Heurtaux, P. Clayette, C. Kreuz, J.-S. Chang, Y. K. Hwang, V. Marsaud, P.-N. Bories, L. Cynober, S. Gil, G. Férey, P. Couvreur and R. Gref, Nat. Mater., 2010, 9, 172-178 https://doi.org/10.1038/nmat2608.

6. L. Jiang and Z. Fan, Nanoscale, 2014, 6, 1922 DOI: 10.1039/C3NR04555B.

7. F. Chekin, S. K. Singh, A. Vasilescu, V. M. Dhavale, S. Kurungot, R. Boukherroub and S. Szunerits, ACS Sens., 2016, 1, 1462-1470 DOI: https://doi.org/10.1021/acssensors.6b00608.

8. S. Han, D. Wu, S. Li and F. Zhang, Adv. Mater., 2014, 26, 849-864 DOI: https://doi.org/10.1002/adma.201303115.

9. G. Ning, Z. Fan, G. Wang, J. Gao, W. Qian and F. Wei, Chem. Commun., 2011, 47, 5976 DOI: $10.1039 / \mathrm{C} 1 \mathrm{CC} 11159 \mathrm{~K}$.

10. L. Ren, K. N. Hui, K. S. Huio, Y. Liu, X. Qi, J. Zhong, Y. Du and J. Yang, Sci. Rep., 2015, 5, 14229 https://doi.org/10.1038/srep14229.

11. S. K. Singh, V. M. Dhavale, R. Boukherroub, S. Kurungot and S. Szunerits, Applied Materials Today, 2016 DOI:10.1016/j.apmt.2016.10.002. 
12. H. Maaoui, S. K. Singh, F. Teodoresu, Y. Coffinier, A. Barras, R. Chtourou, S. Kurungot, S. Szunerits and R. Boukherroub, Electrochim. Acta, 2017, 224, 346-354 DOI: https://doi.org/10.1016/j.electacta.2016.12.078.

13. S. Szunerits, F. Teodurescu and R. Boukherroub, Eur. Polym. J., 2016, 83, 467-477 DOI: https://doi.org/10.1016/j.eurpolymj.2016.03.001.

14. X. Luo and X. T. Cui, Electrochem. Commun., 2009, 11, 402-404 DOI: https://doi.org/10.1016/j.elecom.2008.11.052.

15. F. Teodorescu, L. Rolland, V. Ramarao, A. Abderrahmani, D. Mandler, R. Boukherroub and S. Szunerits, Chem. Commun., 2015, 51, 14167-14170 DOI: 10.1039/C5CC05539C.

16. J. G. Hardy, D. J. Mouser, N. Arroyo-Curras, S. Geissler, J. K. Chow, L. Nguy, J. M. Kim and C. E. Schmidt, J. Mater. Chem. B, 2014, 2, 6809 DOI: 10.1039/C4TB00355A.

17. C. L. Weaver, J. M. LaRosa, X. Luo and X. T. Cui, ACS Nano, 2014, 8, 1834-1843 DOI: https://doi.org/10.1021/nn406223e.

18. L. Wu, J. Wang, N. Gao, J. Ren, A. Zhao and X. Qu, Nano Res., 2015, 8, 2400-2414 DOI: https://doi.org/10.1007/s12274-015-0750-x.

19. M. P. Rogers and L. Blackburn, Clinical J. Oncology Nursing, 2010, 14, 500-504 DOI: https://doi.org/10.1188/10.CJON.500-504.

20. A. S. Can, M. S. Erdal, S. Gungor and Y. Ozsoy, Molecules, 2013, 18, 5455-5471 DOI: https://doi.org/10.3390/molecules18055455.

21. R. M. Al Abood, S. Talegaonkar, M. Tariq and F. J. Ahmad, Colloids Surf., B, 2013, 101, $143-$ 151 DOI: https://doi.org/10.1016/j.colsurfb.2012.06.015.

22. H. S. Gwak, I. S. Oh and I. K. Chun, Drug Dev. Ind. Pharm., 2004, 30, 187-194 DOI: https://doi.org/10.1081/DDC-120028714.

23. K. Swain, S. Pattnaik, S. Chandra Sahu, K. Kumar Patnaik and S. Mallick, J. Drug Targeting, 2010, 18, 106-114 DOI: https://doi.org/10.3109/10611860903225727.

24. F. Teodorescu, G. Quéniat, C. Foulon, M. Lecoeur, A. Barras, S. Boulahneche, M. S. Medjram, T. Hubert, A. Abderrahmani, A. Boukherroub and S. Szunerits, J. Controlled Release, 2017, 245, 137-146 DOI: https://doi.org/10.1016/j.jconrel.2016.11.029.

25. H. S. Mahadjan, B. V. Tatiya and P. P. Nerkar, Power Technol., 2012, 221, 168-176 DOI: https://doi.org/10.1016/j.powtec.2011.12.063.

26. L.-L. Li, J.-H. Xu, G.-B. Qi, X. Zhao, F. Yu and H. Wang, ACS Nano, 2014, 8, 4975-4983 DOI: https://doi.org/10.1021/nn501040h.

27. Z. Lu, J. Zhang, Z. Yu, Q. Liu, K. Liu, M. Li and D. Wang, New J. Chem., 2017, 41, 432-436 DOI: $10.1039 / \mathrm{C} 6 \mathrm{NJ} 03260 \mathrm{E}$.

28. X. Shi, H. Wu, Y. Li, X. Wei and Y. Du, J. Biomed. Mater. Res., Part A, 2013, 101, 1373-1378 DOI: https://doi.org/10.1002/jbm.a.34432.

29. O. S. Kluin, H. C. van der Mei, H. J. Busscher and D. Neut, Biomaterials, 2009, 30, $4738-$ 4742 DOI: https://doi.org/10.1016/j.biomaterials.2009.05.012.

30. L. Chu, H. Gao, T. Cheng, Y. Zhang, J. Liu, F. Huang, C. Yang, L. Sji and J. Liu, Chem. Commun., 2016, 52, 6265 DOI: 10.1039/C6CC01269H.

31. P. Gao, X. Nie, M. Zou, Y. Shi and G. Cheng, J. Antibiot., 2011, 64, 625 DOI: https://doi.org/10.1038/ja.2011.58.

32. T. Palaniselvam, K. Kashyap, S. N. Bhange, J.-B. Baek and S. Kurungot, Adv. Funct. Mater., 2016, 26, 2150-2162 DOI: https://doi.org/10.1002/adfm.201504765.

33. G. Cevc, G. Blume, A. Schatzlein and D. Gebauer, Adv. Drug Delivery Rev., 1996, 18, 349378 DOI: https://doi.org/10.1016/0169-409X(95)00091-K.

34. R. C. Mashru, V. B. Sutariya, M. G. Sankalia and J. M. Sankalia, Pharm. Dev. Technol., 2005, 10, 241-247 DOI: https://doi.org/10.1081/PDT-54437.

35. H. S. Gwak, I. S. Oh and I. K. Chun, Drug Development and Industrial Pharmacy, 2004, 30, 187-194 DOI: https://doi.org/10.1081/DDC-120028714 . 